\title{
Los valores detrás de la privacidad
}

\section{Values behind Privacy}

\section{Isabel Turégano Mansilla}

\author{
Autora: \\ Isabel Turégano Mansilla \\ Universidad de Castilla - La Mancha, España \\ Isabel.Turegano@uclm.es \\ https://orcid.org/0000-0003-1980-4351 \\ Recibido: 22-10-2019 \\ Aceptado: 26-1-2020

\section{Citar como: \\ Turégano Mansilla, Isabel, (2020). Los valores detrás de la privacidad. Doxa. Cuadernos de Filosofía del Derecho, 43, pp. 255-283. https://doi.org/ 10.14198/DOXA2020.43.10 \\ Licencia: \\ Este trabajo se publica bajo una Licencia Creative Commons Atribución 4.0 Internacional. \\ cc) (i)}

(C) Isabel Turégano Mansilla

\begin{abstract}
Resumen
El trabajo tiene por objeto distinguir los valores e intereses que se tratan de proteger bajo el concepto genérico de privacidad. Junto al planteamiento liberal de esos valores, en términos de aislamiento, intimidad, confidencialidad o autodefinición, y las aproximaciones más recientes a la privacidad informacional o protección de datos personales, se expone cómo el entorno digital ha supuesto un cambio cualitativo en la comprensión del concepto que favorece especialmente la consideración de su dimensión social y política. La privacidad tiene relevancia pública en cuanto que se trata de un bien colectivo, es un elemento constitutivo de una sociedad democrática, debe condicionar una esfera pública inclusiva y plural y requiere transparencia y control públicos del sistema socio-técnico institucional. Por ello, se argumenta que la protección de la privacidad no puede organizarse conforme a un modelo de autogestión individual, sino con medidas y normas colectivas públicas y generalmente justificadas. Agentes privados y públicos deben estar conjuntamente comprometidos con la garantía de la igual capacidad de todo individuo de pensar, elegir, vivir y participar en que puede sintetizarse el núcleo complejo del concepto de privacidad.
\end{abstract}

Palabras clave: Privacidad; intimidad; público; big data; protección de datos personales; tecnologías de la información; entorno digital; poder.

\begin{abstract}
This work aims at distinguishing the diverse values and interests protected by the right to privacy. In addition to the liberal approach to these values, in terms of seclusion,
\end{abstract}

\footnotetext{
* El presente trabajo fue presentado en una versión inicial en la IX edición del postgrado en Argumentación Jurídica de la Universidad de Alicante y en el XVII Seminario Jurídico Interdisciplinar «Globalización y Derecho" celebrado en la Universidad Carlos III de Madrid. Agradezco todos los enriquecedores comentarios que se hicieron al mismo por los y las participantes en ambos eventos.

El trabajo se ha realizado en el marco del Proyecto AICO/2017/161 de la Generalitat Valenciana titulado «La era digital; nuevos problemas para el Derecho» y dirigido por la profesora Olga Fuentes de la Universidad Miguel Hernández.
} 
intimacy, confidentiality or self-definition, and the most recent approaches to informational privacy or personal data protection, it is presented how the digital environment has entailed a qualitative change that primarily supports the consideration of the social and political dimension of privacy. Privacy has public relevance inasmuch as it is a collective good, it is a constitutive element of a democratic society, it facilitates an inclusive and plural public sphere and requires public transparency and control of the institutional socio-technical system. Therefore, it is argued that the protection of privacy cannot be organized according to an individual self-management model but through public and generally justified collective measures and norms. Private and public agents must be jointly committed to guaranteeing the equal capacity of every individual to think, choose, live and participate in which the complex core of the concept of privacy can be synthesized.

Keywords: Privacy; intimacy; public; big data; personal data protection; information technology; digital environment; power

\section{INTRODUCCIÓN}

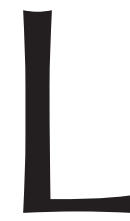

a privacidad está considerada como un valor que, de un modo u otro, está en el centro de lo que hace que valga la pena vivir. Las razones que pueden alegarse para sostener una pretensión legítima a la privacidad son diversas y, aunque pueden considerarse interconectadas por sustratos normativos comunes, aportan la base para diferentes modelos éticos y políticos. Esta relativa indeterminación o flexibilidad ha generado un debate intenso acerca del sentido y adecuación de la protección de lo privado. Gran parte de la literatura sobre privacidad le ha atribuído tradicionalmente valor en virtud de argumentos relativos a la protección de intereses individuales, argumentación que, como ha puesto de manifiesto la teoría feminista, ha ocultado en muchas ocasiones la protección de modelos familiares y sociales jerarquizados y ha minusvalorado el grado en que la realización de los valores que protege la privacidad depende de la cooperación activa de lo político. Los debates más interesantes de nuestros días muestran que el valor de la privacidad no se agota en esa dimensión personal o individual, sino en la dimensión social y política de la privacidad que la muestra como un elemento esencial de cualquier proyecto democrático que trate de evitar la homogeneización y la exclusión.

El valor de la privacidad está hecho de una diversidad de intereses dignos de protección. Mucha de la literatura sobre privacidad se ha esforzado en mostrar que no es, como sugirió Thomson, sin más un valor confuso y redundante respecto de otros valores, sino un concepto con contenido y sentido propios. Pero la cuestión es compleja porque no hay un único sentido en que se hable de privacidad ni una única manera de protegerla y promoverla. Detrás de la privacidad no hay solo intereses personales (aislamiento, intimidad, autonomía, confidencialidad) ni una única pretensión que legítimamente se trate de hacer valer bajo su amparo. Con toda razón, el conocido juez Louis Brandeis afirmó que la privacidad era el «más comprehensivo» de los derechos ${ }^{1}$.

1. Voto disidente en Olmstead v. United States (1928). 
Se podría plantear una idea que va vertebrando los diferentes intereses o dimensiones del concepto y que lo convierten en un elemento relevante en el discurso moral y político: la de la capacidad del individuo de pensar, elegir, vivir y participar. Los intereses que se pueden englobar en esa idea, que se entremezclan y que se consideran conjuntamente dignos de protección desde el valor de la privacidad, difícilmente se pueden resumir en un elenco delimitado. Entre ellos estarían las ideas de aislamiento, confidencialidad, inaccesibilidad, intimidad familiar y afectiva, capacidad de decidir cómo presentarse a otros, protección de datos personales o autodeterminación. Cada una de ellas van apareciendo en los cuatro apartados de este trabajo relativos a las diferentes dimensiones de la privacidad que cobran peso y sentido de modo separado y que constituyen un haz plural de razones por las que la privacidad es valiosa y útil en el debate moral y político.

El primer apartado de este trabajo agrupa dos dimensiones distinguibles -lo íntimo y la vida privada- que emplean los argumentos tradicionales que valoran la privacidad por su protección de intereses individuales. El segundo introduce dos elementos que el creciente desarrollo de las tecnologías de la información ha convertido en el foco de gran parte del debate sobre privacidad: la idea positiva de control y el carácter material y objetivo del contenido del derecho, los datos personales. El tercero muestra cómo el cambio a un entorno digital transforma muchas de las consideraciones morales en juego en cuestiones cualitativamente diferentes, que dotan de especial trascendencia la última de las dimensiones abordada en el cuarto apartado: la dimensión social y política de la privacidad. Reducir la privacidad a un interés individual es insuficiente para dar cuenta de muchas de las preocupaciones planteadas en los debates sobre las tecnologías de la información. Los rápidos avances tecnológicos están intensificando la dimensión social de la privacidad, en la medida en que el carácter progresivamente cuantificado de nuestras sociedades genera cambios en el modo de ejercer el poder y de controlar nuestras vidas. Al tiempo que la privacidad se disuelve en un contexto de creciente exposición, lo público se desmorona ante el desinterés de agentes e instituciones privados y públicos de asumir sus responsabilidades. Las cuestiones que expongo podrían plantearse desde cualquiera de los lados de la dicotomía entre lo público y lo privado. Pero si las abordo desde la perspectiva del segundo es porque en el contexto de los debates jurídicos sobre nuestra era digital el empleo generalizado del término «privacidad» confunde planos y problemas que deberían separarse. El discurso dominante sobre la privacidad como protección de datos personales hace aparecer los problemas fundamentalmente como una cuestión de autodeterminación individual. Lo que está en juego, en cambio, es una cuestión moral y política más profunda acerca del poder en nuestras sociedades.

El término privacidad realmente es un neologismo o un anglicismo cuyo significado en nuestra lengua es sumamente ambiguo y no coincide ni con la idea de intimidad ni la de vida privada, al tiempo que se emplea para referirse a ideas estrechamente vinculadas con ellas. El término viene siendo cada más aceptado en los usos sociales, políticas y normativas de reglamentación de la protección de datos o directrices lingüísticas 
y es común verlo utilizado en los debates jurídico-doctrinales. Nuestra legislación y jurisprudencia emplean en ocasiones el término como concepto más amplio que el de intimidad que abarca un conjunto más global de facetas de la personalidad que excluyen legítimamente la interferencia ajena y merecen protección ${ }^{2}$. Los tribunales vienen siendo conscientes de la necesidad de aunar los diferentes intereses y valores vinculados a la privacidad bajo el amparo de un régimen de protección común cada vez más ampliado. Recientes sentencias de nuestro Tribunal Supremo plantean ir más allá del tratamiento constitucional fragmentado de cada uno de los derechos que convergen en el uso de las tecnologías de la información afirmando la existencia de un derecho al propio entorno virtual ${ }^{3}$.

En general, creo que existe un consenso creciente acerca de que la privacidad es un concepto más amplio que el de intimidad que incorpora diversas facetas referidas a la cualidad o condición del individuo de poseer vida personal ajena a lo público y libre de injerencias (Díaz Rojo, 2002). Desde un punto de vista crítico, este empleo extensivo del término permite mostrar la diversidad de intereses dignos de protección que giran en torno a aspectos de la dignidad, la identidad, la libertad o la participación. Me refiero a continuación a cuatro ámbitos de la privacidad (lo íntimo y la vida íntima o privada, el derecho a la protección de datos personales, privacidad en el entorno digital y la dimensión social de la privacidad) que se refieren a intereses y valores diversos que están detrás de lo privado. No pretendo hacer un planteamiento jurídico-dogmático ni reflejar ninguna realidad moral, sino hacer distinciones necesarias para situar correctamente los problemas que se plantean en nuestros días para su deliberación y crítica.

\section{LO ÍNTIMO Y LA VIDA ÍNTIMA O PRIVADA}

El sentido más inmediato de la intimidad se identifica con el primero de los «estados de privacidad» a los que se refirió Alan Westin (1967). La soledad es aquel estado en el que

2. La Exposición de Motivos de la LO 5/1992 aclara que habla de privacidad como distinta de la intimidad. La primera la considera más amplia que la segunda, "pues en tanto la intimidad protege la esfera en que se desarrollan las facetas más singularmente reservadas de la vida de la persona -el domicilio donde realiza su vida cotidiana, las comunicaciones en las que expresa sus sentimientos, por ejemplo-, la privacidad constituye un conjunto, más amplio, más global, de facetas de su personalidad que, aisladamente consideradas, pueden carecer de significación intrínseca pero que, coherentemente enlazadas entre sí, arrojan como precipitado un retrato de la personalidad del individuo que este tiene derecho a mantener reservado». La Ley 25/2007, de Conservación de Datos Relativos a las Comunicaciones Electrónicas y a las Redes Públicas de Comunicaciones menciona solo la privacidad en su preámbulo. La Ley Orgánica de 1999 no empleaba el término. La actual solo lo emplea en dos ocasiones: habla de privacidad en el sector de las comunicaciones electrónicas y se refiere a un representante de los profesionales de la protección de datos y de la privacidad como miembro del Consejo Consultivo de la Agencia Española de Protección de Datos. La jurisprudencia emplea también el término como diferente de la intimidad (veáse entre otras muchas las STC 58/2018 y STS 3754/2018).

3. Vid. SSTS 342/2013, de 17 de abril; 97/2015, de 24 de febrero; 786/2015, de 4 de diciembre; 204/2016, de 10 de marzo; 426/2016, de 19 de mayo. 
el individuo se separa del grupo y se libera de la observación por otros, sometiéndose solo a las sensaciones físicas y al diálogo con la propia mente y conciencia. Lo íntimo es «el ámbito de los pensamientos de cada cual, de la formación de decisiones, de las dudas que escapan a una clara formulación, de lo reprimido, de lo aún no expresado y que quizás nunca lo será, no solo porque no se desea expresarlo, sino porque es inexpresable» (GARZÓn VALDÉs, 2003: 16). Resulta así indecible e inaccesible (CASTILla Del Pino, 1989a: 9). Cuando somos observados estamos en gran parte determinados por lo que imaginamos que es percibido desde la perspectiva de los otros y el libre funcionamiento de nuestros sentimientos, fantasías y pensamientos personales queda condicionado (Wasserstrom, 1984: 324; NAgeL, 1998: 4).

La intimidad no solo se produce en la soledad o el aislamiento, sino también en el seno de las relaciones con otros, siempre que se es capaz de crear una barrera psicológica contra la intrusión no querida. Incluso en nuestras relaciones más íntimas la comunicación de nuestra interioridad a otros es siempre incompleta y se retienen aspectos internos que se estiman demasiado personales o no confesables. Además de esta reserva y de la soledad, Allan Westin habla de un tercer estado que implica privacidad. El anonimato hace posible que un individuo que se encuentra en un lugar público pueda estar liberado de ser identificado o vigilado y, de este modo, no verse sometido a las reglas de comportamiento y roles que operarían si quienes le observan le conocieran (WESTIN, 1967) ${ }^{4}$.

La idea de intimidad no ha existido siempre. Su fundamento se encuentra en la defensa liberal de la necesidad de una esfera reservada al individuo para el pleno desarrollo de su personalidad (BÉJAR, 1988). De la idea de dignidad humana deriva el derecho y la obligación de cada individuo de desarrollarse a sí mismo como persona así como la obligación de contribuir al libre desarrollo de los demás. En términos dworkinianos, ser persona supone ser merecedor de igual consideración y respeto, lo que se traduce en un principio de auto-respeto, conforme al que es una cuestión de importancia intrínseca y objetiva que toda vida humana sea bien vivida, y en la especial responsabilidad de todo ser humano en la identificación y persecución de lo que considera relevante en su vida. La intimidad protege un espacio para el individuo con el objeto de que pueda identificar sus fines y preferencias para desarrollar esa vida propia.

Así concebida la intimidad desempeña algunas funciones esenciales para el individuo en las sociedades democráticas. En primer lugar, el espacio íntimo libera al sujeto de la tensión emocional que supone desempeñar los roles sociales que ha asumido y acatar las normas sociales imperantes. La expectativa de tener un resquicio de intimidad que permita idear ciertas desviaciones es una característica de una sociedad libre que alivia la presión del sometimiento a un orden colectivo. En segundo lugar,

4. En un ensayo reciente, La revolución de las flâneuses, AnNa María IgLesia (2019) reivindica para las mujeres el tipo literario de la Francia decimonónica que Baudelaire describió como el observador apasionado que quiere «ver el mundo, estar en el centro del mundo y quedar oculto al mundo... que disfruta en todos los lados de su incógnito" (BAUDELAIRE, 2009: 36). Ciertamente el anonimato tiene una doble faz, puesto que también facilita conductas inmorales o fraudulentas dificultando la atribución de responsabilidades (LAPORTA, 2018: 28). 
en ese espacio íntimo el individuo afirma la singularidad de su pensamiento e ideas, esto es, aquello que lo distingue de los demás. Tomar como base al individuo real, no abstracto, es lo que permite tomar conciencia de las diferencias. ${ }^{5}$ Y, en tercer lugar, esa posibilidad de experimentar, descubrir, fantasear y meditar sin rendir cuentas a los otros es la que permite el ejercicio pleno de la autonomía. La privacidad se identifica también con la capacidad de definirnos como sujetos singulares así como la libertad que hace posible organizar la propia vida de acuerdo con los gustos e inclinaciones propios. Si la intimidad propiamente dicha puede representarse en la categoría de un espacio físico o mental blindado a la intromisión externa, la autonomía apela a una categoría también enmarcable en la noción de privacidad y que puede expresarse como decisión o elección. Lo privado se refiere a la capacidad del individuo de adoptar ciertas decisiones relevantes que a él afectan sin interferencia externa, manteniendo las razones de su acción fuera del escrutinio público (KANG, 1998: 1202-1203). La violación de la privacidad puede ser una forma extrema de humillación en cuanto que restringe el control que los individuos ejercen sobre lo que se supone que debería estar dentro de su control (Margalit, 1996: 204).

Pero ambas ideas, la de intimidad y la de autonomía, pueden separarse conceptualmente. Las actuaciones íntimas «no pueden observarse y solo se las puede inferir a través de lo que el sujeto dice o hace, incluso con su inhibición o su silencio" (CASTILLA DEL PIno, 1989b: 29). La autonomía supone la proyección externa de esas acciones en decisiones y elecciones. Puesto que la intimidad en sí es inobservable, lo que la vulnera es dar a conocer o atribuir una intención oculta tras una actuación privada o pública de la que se puede inferir. El observador de tal actuación que la transmite a otros debe atenerse a lo observado no a la intención de la actuación observada, que es íntima (CASTILla DEL Pino, 1989b: 30$)^{6}$. Las inferencias o juicios acerca de las intenciones individuales puedan llegar a afectar muy negativamente a nuestro derecho a la intimidad y requerir protección jurídica. En gran parte, ello puede venir condicionado por el modo en que los avances tecnológicos sean capaces de traducir los estados mentales en datos cognoscibles y estos puedan hacerse públicos o ser manipulados. Los algoritmos permiten ya que los datos recopilados en dominios diversos sean agregados para generar perfiles

\footnotetext{
5. La relegación histórica de las mujeres al ámbito privado ha supuesto, entre otras cosas, el hecho de que en ese ámbito se les haya negado el estatus de individualidad, apareciendo como las «idénticas» que quedan invisibilizadas bajo una categoría genérica (Aмorós, 1991: 52). El rechazo feminista a una privacidad acrítica y excluyente no es incompatible con la necesidad de reconocer a cada mujer una intimidad propia, con su riqueza de pensamientos y aspiraciones. La conocida imagen de Virginia Woolf de una habitación propia representa un espacio individual como «anhelo por una utopía individual, por huir momentáneamente de las relaciones humanas, un intenso egocentrismo nuevo para las mujeres» (AleXANDer, 1998: 135). La intimidad se opone aquí a la privacidad de la familia y las relaciones personales. Es desde esa individualidad desde donde el hombre y la mujer pueden forjar y reconocer la realidad y su identidad al margen del modelo de sujeto universal y neutro que está en el centro del pensamiento moral dominante. En este sentido, el feminismo no tiene por qué ser necesariamente incompatible con la defensa del valor de la privacidad, como han sostenido Allen (1988) o Cohen (1999), entre otras muchas.

6. Como afirma Manuel Toscano, es posible que alguien «que nos conozca bien, acierte a ver lo que nos pasa, a veces mejor que nosotros mismos» (2017: 542).
} 
reveladores de quiénes somos a partir de la evidencia de lo que hacemos y decimos. Cada vez más el uso de datos se extiende a la elaboración de perfiles psicológicos que permiten identificar creencias, preferencias u orientaciones que el individuo preferiría no dar a conocer a terceros. El riesgo de estas inferencias invasivas y predictivas ha llevado a la defensa de un «derecho a inferencias razonables» (Wachter y Mittelstadt, 2019).

Lo íntimo es sumamente poroso, hasta el punto de que puede pensarse que, por ello, es un concepto irrelevante. Por una parte, tiende a exteriorizarse y convertirse en elecciones y acciones privadas o públicas. Es solo lo que decidimos y hacemos con proyección exterior lo que es objeto de consideración moral, mientras que lo que permanece en la interioridad escapa a la valoración moral (GARZón VALDÉs, 2003: 17). Por otra parte, lo íntimo se ve atravesado y modelado por pautas y usos relacionales y sociales. El individuo no es un sujeto abstraído de un entorno y unas circunstancias. Cada persona configura su vida y preferencias como respuesta personal a sus propias capacidades y sus circunstancias sociales y culturales. Afrontar el reto en que consiste una vida supone desarrollarla de modo adecuado a las propias situaciones o a las propias expectativas culturales (DwORKIN, 2003: 279). El contexto comunitario y cultural provee de modos de concebir y vivir el mundo que rodea al individuo. Además, desde una concepción relacional de la persona, es en la capacidad de actuar con otros y de deliberar conjuntamente sobre las condiciones sociales de todos donde el sujeto se realiza más plenamente. Esta dimensión social es indisociable de las otras ideas que están detrás de la privacidad. Sin embargo, considero que ello no supone renunciar a este primer valor del sentido más íntimo de la privacidad. Ninguna cultura o proyecto colectivo expresa por sí misma el ideal humano en abstracto. Por ello es esencial, como pensaba John Stuart Mill, la capacidad del individuo de elegir su propio plan de vida y cambiar su entorno sin dejar que las opiniones y las leyes lo determinen por completo. En ultimo término es la actitud crítica y reflexiva del individuo ante el medio el contenido más básico de la intimidad. Es la competencia de cada individuo para la introspección y la revisión parcial de identidades y concepciones del bien sobre la base de nuevos discernimientos la que le permite conformar y afirmar una identidad irrepetible (Cohen, 1999: 31, 34). La intimidad, en este sentido, se traduce en la necesidad de experimentar con libertad, de perderse por espacios que queremos explorar sin consejos ni críticas, pudiendo demandar un «minimalismo digital» (NEWPORT, 2019: 103).

A lo que se suele hacer referencia, especialmente en el ámbito jurídico, con el término de «intimidad» no es principalmente este primer aspecto al que acabo de referirme, esto es, lo recóndito de nuestra vida interna, sino, sobre todo, al modo en que los sujetos revelan junto a otros lo que cada uno es. Lo privado adquiere un sentido diferente cuando se presenta como el ámbito en que estamos o aparecemos con otros. Se suele emplear el término de intimidad y «lo privado» en relación con aquel ámbito reservado a un tipo de situaciones y relaciones interpersonales donde imperan los deseos y preferencias individuales y vedado a la mirada de terceros, aunque es potencialmente observable. Es el dominio en el que tratamos de proyectar y hacer valer con otros nuestros deseos y preferencias. El velo que nos protege de la exposición pública es levantado 
parcialmente en esta esfera para admitir a «otros particulares». Este ámbito desempeña también una función importante en el desarrollo de una vida interna porque permite explorar sentimientos y actuaciones no públicos en un contexto de relaciones (NAGEL, 1998: 20).

El desvelamiento de la propia intimidad conlleva riesgos, tales como el de ofrecer una versión distorsionada de nuestra propia personalidad, de colocarnos en situaciones de inferioridad en nuestras relaciones personales, o de encontrarnos con la desaprobación u hostilidad de los demás. Es la capacidad de decidir y controlar quién tiene acceso a uno mismo, tanto en sentido físico como respecto del conocimiento de lo más próximo a nosotros, el atributo más importante de esta intimidad compartida y el que nos permite adaptarnos a un mundo de relaciones sociales diversas ${ }^{7}$. La privacidad significa acceso restringido y control, esto es, restricción de intromisiones ilegítimas en la esfera protegida y poder para determinar libremente nuestra conducta y relaciones. Además, la intimidad implica restricciones y responsabilidades de respetar la distancia respecto de los otros que las expectativas sociales generan en las distintas relaciones sociales en las que estamos insertos (MARMOR, 2014: 6-7). Especialmente exige confidencialidad y reserva como consecuencia de la delimitación contextual en que nos mostramos o damos a conocer detalles de nuestras vidas. Lo privado no es el tipo de acontecimiento o conocimiento que se exterioriza, sino el tipo de relación y el entorno en el que los hechos o el intercambio de información ocurre. Esa relación o entorno es capaz de generar la confianza o el ambiente para expresarse en libertad, esto es, para no tener la intención ni la expectativa de que lo que se hace o se comenta llegue a ser visto o escuchado por otros fuera de esa relación ${ }^{8}$. La lesión a la privacidad, en este sentido, no tiene que ver con la difusión de un conocimiento o información personales cuanto con la deslealtad derivada de la ruptura de la confianza y las expectativas generadas (Post, 2001: 2091-92). Es en este sentido en el que la falta de respeto a la privacidad se concibe como una ofensa a la dignidad, esto es, a la exigencia intersubjetiva de respeto. Ofende la privacidad la exposición del individuo sin las protecciones derivadas de las formas de respeto que generalmente gobiernan nuestras vidas.

Existe un continuo entre lo íntimo y lo privado. En el ámbito íntimo desarrollamos y fraguamos nuestros deseos, opiniones o pensamientos. El contenido y sentido de lo privado radica en poder compartir esa vida interior con ciertas personas y en ciertas relaciones. Si lo íntimo es necesario para nuestra autonomía y el libre desarrollo de

7. La idea de privacidad como inaccesibilidad se encuentra en muchos de los textos clásicos de la literatura anglosajona sobre privacidad. Entre otros puede verse en GAvison (1980); BoK (1983); AlLEN (1988); o MOOre (2003).

8. Desde una concepción subjetiva de la intimidad puede pensarse que lo que resulta protegible no lo es solo por su contenido personal, sino por el contexto en el que el sujeto considera posible la comunicación en libertad y confianza. Ese contexto se considerará protegible por la intimidad si se caracteriza por un deseo de compartir experiencias importantes, no solo por un deseo recíproco de compartir información (ReIman 1976: 33). El verdadero conocimiento de otra persona es la culminación de un lento proceso de mutua revelación. «Nos exige el retiro gradual de las máscaras sociales, la forja gradual de la confianza, que lleva al intercambio de revelaciones personales» (Rosen, 2000: 8). 
nuestra personalidad, la vida íntima o privada provee el espacio para desarrollar nuestra libertad, tener relaciones personales y actos íntimos diversos e intercambiar información personal, lo que, a su vez, nos permite explorar nuevas facetas propias. La privacidad se aproxima a la intimidad tanto más cuanto las relaciones privadas están más orientadas o expresan especialmente emociones o sentimientos de afecto, amor o cuidado (INNEss, 1992: 74) o, en palabras de Parent, en cuanto esas relaciones supongan "compartir las experiencias, aspiraciones, debilidades y valores más íntimos» (1983: 275). Las relaciones estrechas y su carácter cotidiano favorecen que se compartan creencias, ideas o pensamientos que no exponemos en otras relaciones. La protección de la privacidad se justifica entonces por las mismas razones que justifican la protección de la intimidad. Gran parte de la doctrina y la jurisprudencia relativas al derecho a la intimidad debe entenderse como referida a la privacidad en este sentido de prolongación de nuestra interioridad hacia esferas concomitantes en las que se exteriorizan los pensamientos o sentimientos que constituyen la esfera íntima mediante conductas o acciones individuales o relaciones con otros.

Pero no siempre la protección de las relaciones privadas se funda es que sean expresión de esos sentimientos más íntimos. La privacidad también protege otras formas de socialización humana delimitadas. Otras relaciones e interacciones sociales distintas de las afectivas pueden ser también importantes en la formación y desarrollo de la individualidad, a pesar de no estar vinculadas a los afectos. Sin duda, las relaciones comunitarias y los lazos asociativos tienen un papel central en el desarrollo humano. Pero también pueden serlo otros vínculos sociales; por ejemplo, en la tradición hegeliana y marxista, el trabajo es un proceso de autoproducción donde se revela lo específico del ser humano. Las relaciones profesionales, económicas, educativas, sanitarias, administrativas o laborales se desenvuelven en espacios distintos de las relaciones familiares o afectivas, ante audiencias más amplias y tienen un carácter más impersonal (CAMPs, 1989: 63-64). Son esferas más abiertas a la observación y más sujetas a control para el cumplimiento de las obligaciones y los fines propios de cada una. Pero demandan también reserva y se incluyen en la esfera de protección de la privacidad. La delimitación de su alcance y límites en cada uno de esos contextos requiere atender su especificidad y fines propios. Cada uno responde a patrones diferentes que condicionan el significado de la privacidad, esto es, determinan la diferente expectativa de privacidad que es razonable tener en cada caso?.

9. Así, por ejemplo, en el ámbito bancario, el manejo de ciertos datos personales puede afectar la intimidad. Sin embargo, su protección no abarca la información económica y financiera que debe ser conocida por la Administración. En el ámbito profesional el fin propio de la actividad exige el secreto profesional o los secretos comerciales. Ello no excluye el deber de denunciar hechos delictivos o actos ilícitos, que puede fundamentar la actuación de un particular vulnerando la privacidad impuesta por la profesión para actuar en favor del interés general. En lo laboral la actividad se realiza en muchos casos en espacios parcialmente cerrados al público que generan expectativas de privacidad. Pero encuentran su límite en prácticas irregulares o incumplimiento de condiciones de la relación laboral. En todo caso, la protección de la privacidad exige siempre garantías, como la comunicación al trabajador, de especial importancia en un tipo de relaciones que no son horizontales. En 
La vida privada se desarrolla de modo paralelo a las obligaciones públicas, con sus propias pautas y usos que rigen los roles, expectativas, acciones y prácticas en una diversidad de relaciones interpersonales. El espacio privado se reglamenta de modo flexible y relativamente independiente, aunque eso no convierte en menos imperativas las exigencias que se generan. Lo privado es un espacio de poder, que puede ocultar subordinación y violencia. Su protección respecto de la intervención pública puede suponer habilitar un ámbito de impunidad respecto del abuso y la opresión. Por ello, no se puede afirmar que ciertas conductas se justifican si se realizan en el ámbito privado. Suponer tal cosa es fruto de la confusión habitual entre lo íntimo y la vida privada que atribuye a esta una inmunidad injustificable. La vida privada ha de regirse por los mismos principios que la esfera pública y solo será merecedora de un respeto y protección condicionados a que las relaciones o acciones que en ella se desarrollan sean deseables o moralmente neutras y no impliquen subordinación. La intervención político-jurídica en la privacidad es necesaria para asegurar la libertad e igualdad individuales. Al mismo tiempo, ningún aspecto de la vida personal debería relegarse de modo forzoso a la privacidad y ser excluida de la discusión y expresión públicas (Young, 1990: 120).

\section{PRIVACIDAD COMO PROTECCIÓN DE DATOS PERSONALES}

Social y jurídicamente la intimidad fue interpretándose esencialmente en su sentido positivo, no ya como aislamiento, cuanto como facultad o poder de revelar y proteger aspectos y circunstancias de nuestra intimidad o nuestras relaciones personales ${ }^{10}$. Además, la intimidad ha ido adquiriendo un sentido más objetivo que subjetivo. Lo privado alude a la información o datos personales que, en cuanto elementos materiales, están más expuestos a la difusión y abuso. El desarrollo acelerado de las tecnologías de la información en las últimas décadas ha puesto el foco en estas facetas de la privacidad otorgándoles cierta autonomía frente a otros aspectos o dimensiones de la misma. El Derecho y los usos sociales habrán de reemplazar los muros y puertas que han sido barridos por las nuevas herramientas tecnológicas (LEver, 2013: 66).

La privacidad otorga al individuo la potestad de revelar o compartir información personal de forma selectiva. Cuál sea el tipo de información que el individuo se ve libre para compartir será diferente en función de la naturaleza de la relación, que determinará el tipo y grado de conocimiento sobre cada uno que es apropiado tener (RACHELs, 1975: 328). Los diferentes tipos de relaciones exigen diferentes esquemas de comportamiento social y generan diferentes expectativas sociales acerca de qué aspectos de uno mismo se revelan. Desvelar información sobre nosotros con propósitos delimitados

muchos otros ámbitos, como el educativo o el sanitario, la información que se comparte se revela de forma restringida y para un fin concreto.

10. Charles Fried escribió que la privacidad «no es simplemente una ausencia de información sobre nosotros en las mentes de los otros; más bien es el control que tenemos sobre la información acerca de nosotros» (1968: 482). 
(médicos, financieros, jurídicos, laborales, etc.) supone una exposición forzada por un fin específico. Compartir secretos con un amigo, por el contrario, es un acto constitutivo de nuestra amistad (Margalit, 1996: 209; Gerstein, 1978: 76). Por tanto, es el entorno el que determina en cada caso qué flujo de la información se puede predecir razonablemente que se produzca (Marmor, 2014: 9-10). El entorno de las nuevas tecnologías es sumamente dinámico y cambiante y pone en riesgo el legítimo interés en esa predecibilidad razonable. Pero el problema no es tanto su carácter cambiante, sino la incertidumbre y desconocimiento generalizados acerca de los procedimientos conforme a los que fluye la información, como señalaré más adelante.

Concebida como control sobre la información personal, la tutela de la privacidad se ve permeada, especialmente en la cultura jurídica anglosajona, por la visión iusprivatista de los derechos conforme a la que la libre circulación de la información y de los datos personales son un elemento esencial para la prestación de servicios al consumidor y se otorga preferencia al principio de autodeterminación que supone la preeminencia de las soluciones basadas en la autorregulación y el consentimiento (CATE, 2000; Martínez, 2014). De modo coherente con sus raíces históricas, el concepto de intimidad, ligado al individualismo liberal, se configura como un derecho de cuyo objeto su titular puede disponer ${ }^{11} \mathrm{y}$, por tanto, como derecho a decidir sobre cómo y en qué medida comunicar información personal, análogo al derecho de propiedad. Los datos adquieren un valor autónomo de contenido patrimonial, al margen del valor que poseen en relación con la personalidad. Detrás de esta concepción está la preferencia por una visión de la privacidad desde la perspectiva de la autonomía en lugar de la dignidad, es decir, desde su consideración como capacidad para adoptar decisiones personales sin interferencias externas en lugar de como exigencia de respeto recíproco ${ }^{12}$.

La privacidad como protección de datos personales se considera un derecho independiente del derecho a la intimidad por diversas razones. En primer lugar, porque se refiere específicamente a la información personal que puede ser recopilada, analizada, tratada y difundida o hecha accesible a terceros. Un dato personal es cualquier información (número, sonido, imagen, dirección de identificación, etc.) relativa a una persona identificada o identificable. No se refiere al conocimiento íntimo de una persona en su complejidad, sino a datos cuantificables y clasificables.

11. La defensa de la privacy basada en el modelo propietario la concibe esencialmente como garante de la propiedad privada ante las intromisiones del Estado (prohibición de registros, aprehensiones de bienes o documentos, interceptación de comunicaciones etc. sin autorización judicial y causa justificada). Se protege conforme a la regla del trespass: necesidad de que se produzca algún tipo de intromisión física. Si se vulnera la privacidad al saber algo de otra persona no es porque se conozca un hecho sobre él o ella, sino por el modo en que se obtiene esa información (Thomson, 1975).

12. Whitman contrapone la concepción anglosajona de la privacidad como libertad, especialmente libertad frente al Estado, a la concepción de la Europa continental que prima la idea de dignidad y de reconocimiento y respeto. En la concepción europea el florecimiento humano requiere la realización individual en formas que el mercado no puede proporcionar, primando la autodefinición sin restricciones a la soberanía del consumidor. La privacidad apela no tanto a un interés material cuanto a bienes inmateriales englobados en la idea amplia de la personalidad (Whitman, 2004: 1181-1184, 1192-1194). 
Por otra parte, la información personal que se protege con aquel derecho no siempre tiene un carácter privado en cuanto referida a las circunstancias, opiniones o sentimientos de la vida íntima de la persona. En muchas ocasiones las razones por las que se protegen los datos personales son diferentes de la intención de evitar las injerencias en nuestra autonomía o nuestra esfera íntima (vAN DEN Hoven, 1997: 34-37). La protección puede orientarse, en primer lugar, a evitar daños derivados de la distribución y uso de la información personal, permitiendo que todos puedan acceder a las tecnologías de la comunicación de modo seguro y sin miedo ${ }^{13}$. En segundo lugar, a eliminar la desigualdad informacional, haciendo posible que el actual intercambio de beneficios o servicios por datos se realice en un contexto de mercado justo y transparente, en el que todos conozcan las condiciones y resultados de sus decisiones, haya libre competencia y exista una igualdad de oportunidades. Y, en tercer lugar, a evitar la injusticia informacional que supone el traspaso de información más allá del contexto y los fines para los que fue recabada, especialmente en casos de usos secundarios que pueden no haber sido siquiera concebidos cuando se recopilaron (MAYER-SCHÖNBERGER Y CUKIER, 2013: 153). Cuando se evalúa si cierta información puede ser compartida hay que tener en cuenta el contexto, la naturaleza de la información en relación con ese contexto, quiénes son los agentes que reciben la información, sus roles sociales, su capacidad de afectar la vida de los sujetos de los datos y sus intenciones en relación con ellos, así como los términos en que se comparte la información y los de otras difusiones futuras (Nissenbaum, 2004: 137). La difusión de datos fuera de ese contexto contribuye a que el individuo sea erróneamente conocido y juzgado por terceros ajenos que no pueden identificar la complejidad que le define (Rosen, 2000: 8). Pero no es solo una cuestión de conocimiento erróneo o mala representación, sino sobre todo de pertinencia o relevancia. Uno de los principios básicos de una ética digital ha de ser la limitación de propósito o necesidad funcional de cualquier selección y aplicación de datos personales.

A pesar de apelar a intereses diferentes, la intimidad es especialmente tenida en cuenta en el desarrollo del contenido y garantías del derecho a la protección de datos. Aquellos datos que afectan al reducto más intimo de la personalidad requieren de especiales garantías, puesto que en este caso es mayor el riesgo de discriminación y vulneración de la dignidad de la persona. La normativa de protección de datos habla de datos especialmente protegidos, entre los que se encuentran datos de salud, ideología, religión, origen racial, vida sexual, relaciones familiares y comisión de infracciones penales y administrativas. La conceptualización de un dato como sensible suele hacerse a partir de criterios materiales conforme a los que serían sensibles aquellos datos que tienen una especial incidencia en la intimidad (PÉrez Luño, 2000: 65) o, más precisamente, que se refieren a la esfera íntima (ToniatTi, 1991: 155). Pero es una cuestión compleja la

13. Aníbal Monasterio habla de cuatro tipos de daños producidos por algoritmos en un monográfico de Dilemata sobre "Ética de datos, sociedad y ciudadanía»: discriminación social, discriminación económica, discriminación de acceso libre a la información y privación de libertad y discriminación y abuso de control (2017: 198-208). 
relativa a qué datos personales deben tener una protección mayor. No está predeterminado que ciertos asuntos personales sean intrínsecamente sensibles o que dependa de la pretensión del propio individuo (norm-dependent o norm-invoking) (WACKs, 2010). Por ello, la relación de datos personales contenidas en los diferentes documentos normativos no debe entenderse como un elenco cerrado. No es solo cada individuo el que controla el grado en que se espera que su intimidad se someta al escrutinio público, sino que depende del modo en que esa delimitación se construya socialmente o en contextos delimitados. Lo que se pueda razonablemente esperar que se mantenga en la intimidad no depende de las preferencias o sentimientos propios de cada individuo, sino del modo en que convencionalmente se interpreta esa razonabilidad de acuerdo con valores y expectativas sociales cambiantes (Schauer, 2003: 8). En todo caso, el tratamiento de las categorías especiales de datos, susceptibles de comprometer más directamente la libertad e intimidad individuales, exige que la ley establezca las garantías específicas adecuadas que aseguren la transparencia, control y tutela efectiva y procuren que los datos no se empleen de forma desproporcionada ni se utilicen para fines distintos de los que justificaron su obtención ${ }^{14}$.

\section{LA PRIVACIDAD EN EL ENTORNO DIGITAL}

El entorno digital convierte el problema de la privacidad en algo mucho más amplio que el control de datos personales. La relevancia creciente del concepto refleja su fuerza expansiva y dinamismo (MARTínez de Pisón, 2016: 411). En realidad, la protección de la privacidad deviene una cuestión cualitativamente diferente, en diferentes sentidos. Debido, en primer lugar, a su extensión: aumento de los aspectos de nuestras vidas susceptibles de ser observados o manipulados, aumento de los modos de recopilación de datos, mayor disponibilidad a compartir en redes públicas información personal, incremento de las posibilidades de acceso, tratamiento y difusión. En segundo lugar, por el modo en que se rompe la bidireccionalidad en la comunicación y se transforma en un flujo multidireccional y horizontal (CASTELLS, 2009: 99-108). Y, en tercer lugar, por los cambios en su dimensión temporal -lo privado está potencialmente disponible para el público y sigue disponible indefinidamente (BAUMAN y LyON, 2013: 31) - y espacial, en cuanto que lo privado no implica tanto aislamiento físico cuanto control en un territorio desespaciado de información y contenidos simbólicos (LuCENA Cid,

14. Así lo ha reconocido el TC, en sentencia de 22 de mayo de 2019, en relación con las opiniones políticas como datos personales sensibles que no quedaban suficientemente protegidos con la previsión del art. 58 bis de la Ley Orgánica del Régimen Electoral General (incorporado por la Ley Orgánica de Protección de Datos Personales y Garantía de Derechos Digitales) que permitía a los partidos políticos recopilarlas en el marco de sus actividades electorales. La disposición ha sido declarada inconstitucional, en primer lugar, porque el legislador no determina de modo específico la finalidad legítima del tratamiento de tales datos; en segundo lugar, por no regular pormenorizadamente el alcance y condiciones de los tratamientos que autoriza; y, en tercer lugar, por no establecer ella misma las garantías adecuadas para proteger los derechos fundamentales afectados. 
2012: 143). Al romper los límites del espacio y del tiempo resulta difícil diferenciar los espacios y momentos en los que se está actuando en el ámbito privado y en el público (Marcilla, 2015: 278).

Estos cambios afectan a aspectos esenciales de la idea de intimidad a la que me he referido en el apartado primero. La generalización de las nuevas tecnologías de la información ha modificado sustancialmente el modo de comprendernos en el mundo y de relacionarnos con los otros. El individuo cede en parte su disposición al ejercicio reflexivo y crítico interior y busca la proyección exterior. La generación de Facebook y Twitter es más abierta en el modo en que comparte su información personal ${ }^{15}$. Frente a la tensión emocional que genera la exposición social, la exclusión se considera una amenaza mayor. Por otra parte, ese clima de sobreexposición contribuye a la inhibición y la autocensura y reduce la capacidad del individuo para la reflexión crítica y la libre experimentación y búsqueda de ideas y propósitos. La relevancia que tienen los datos registrados puede favorecer que las personas se comporten del modo que permita reflejar su mejor imagen en los datos que genera. Se actúa con la consciencia de ser observado y dejar constancia de lo que se hace. Y esa consciencia inspira comportamientos psicológicamente clónicos (Lucas Murillo, 1999: 25).

Especial incidencia en la privacidad tiene el problema de la categorización que genera el tratamiento de los datos. Las nuevas tecnologías se pueden emplear para clasificar a las personas conforme a técnicas digitales y lógica estadística en categorías según su valor estimado y su predisposición a ciertos reclamos, que no necesariamente responden a las segmentaciones demográficas usuales, sino que muchas veces modelan tipos psicológicos. Esta categorización produce, en primer lugar, pérdida de oportunidades. Se puede privar a una persona del acceso a ciertos bienes o servicios que no se ajustan al perfil que se le ha atribuido. En segundo lugar, genera desigualdad. Los códigos de software que nos clasifican están diseñados para distinguir entre un grupo y otro permitiendo que las personas sean tratadas de manera diferente según la categoría en la que se encuentren. Los procesos de clasificación y elaboración de perfiles favorecen la formación de estereotipos sociales que determina la atribución de privilegios y derechos o la exclusión social (Lyon, 2007: 184-185). En tercer lugar, implica pérdida de autonomía. El uso indebido de los datos personales puede suponer cruzar la línea que separa la persuasión legítima de la influencia o control indebidos (KANG, 1998: 1215). Es posible que el tratamiento de datos falsee o fabrique preferencias y las modifique. La personalización que permiten los procesos algorítmicos filtra la información que le llega a cada individuo a partir de un análisis exhaustivo de preferencias, comportamientos o posibilidades de influencia. En cuarto lugar, la categorización simplifica y reduce las alternativas. La personalización que permiten los algoritmos reduce la información

15. Se ha empleado el término de «extimidad» (adoptado por Jacques Lacan con un sentido diferente) para hacer referencia al debilitamiento que se está produciendo de lo introspectivo y el cambio que eso supone en el modo en que nos definimos y construimos nuestra personalidad. La extimidad no supone solo el modo en que aceptamos exponer nuestra interioridad, sino cómo al hacerlo construimos de manera diferente nuestra propia forma de entendernos (SibILIA, 2009). 
que llega a cada individuo excluyendo contenidos que se consideran irrelevantes o contradictorios con sus preferencias o creencias (PARISER, 2017). Y, por último, la categorización reduce la diversidad individual a modelos colectivos de comportamiento. En este sentido, la elaboración de perfiles convierte en realidad la cuestión en otra distinta (Schermer, 2011): el problema no es ya la identificabilidad de los datos respecto de individuos concretos, sino la des-individuación o tendencia a tratar a las personas sobre la base de características atribuidas a un colectivo o grupo con el que se identifica. La cuestión en este caso es que una vez que se ha construido el perfil los individuos no necesitan ser identificados para verse afectados por las informaciones y acciones derivadas del mismo (Mittlestadt ET AL, 2016: 10).

Las posibilidades de recopilar, conservar, relacionar, procesar y transmitir la información personal han adquirido dimensiones impensables cuando se comenzó a gestar la idea liberal de intimidad. La reducción de las acciones y decisiones privadas que se adoptan en el entorno digital a registros y datos informáticos entraña un riesgo evidente de que la conducta privada se cosifique y se reduzca a identificadores manejables y comercializables, convirtiendo al titular del derecho a la intimidad en un mero «suministrador de datos» (Pérez LuÑo, 2017: 362). Somos, sin más, el objeto del que se extrae el producto que interesa, resultado del acopio masivo y agregación de datos (Zuboff, 2019). Cada vez más nos convertimos en lo que los datos registrados y procesados dicen que somos, conformando una «biografía digital» que se antepone a nuestra biografía real ${ }^{16}$. Y eso nos hace más vulnerables ${ }^{17}$. La cantidad creciente de datos disponibles en la red así como las posibilidades de analizarlos buscando patrones recurrentes y correlaciones dentro del conjunto suponen riesgos para los derechos fundamentales (GARriga, 2018: 108-113).

Estas posibilidades crecientes son las que aportan el elemento cualitativo que permite obtener información personal de un sujeto a partir de datos aparentemente irrelevantes (MarTínez, 2007: 51; PÉrez LuÑo, 2017: 343). Empleando la metáfora

16. La identidad digital no logra alcanzar a comprehender la complejidad de la subjetividad, su carácter cambiante e indefinido. Como afirma Maiëte van den Hoven, «las identificaciones hechas a partir de nuestros datos no llegan a respetar a la persona individual, ya que nunca coincidirán con la identidad tal y como la experimenta el sujeto de los datos. Falla porque no concibe al otro en sus propios términos. Por lo tanto, se puede considerar que el respeto por la privacidad de las personas tiene una dimensión epistémica. Es una forma de reconocer la "imposibilidad" de conocer realmente a otras personas y de percibir a los demás en sus propios términos” (Hoven, 1997: 37).

17. Solove seńala que la toma de decisiones sobre nuestros datos se enfrenta con algunos problemas que impiden evaluar adecuadamente los costos y beneficios para prestar un consentimiento válido: problemas de escala, problemas de agregación y de evaluación a largo plazo y del impacto social (2013, pp. 23 y ss.). La autogestión de la privacidad pide a la gente tomar decisiones en un punto temprano en el tiempo y en una serie de casos aislados. Pero las verdaderas consecuencias para las personas por el uso de esa información no pueden ser conocidas cuando se toman estas decisiones (casi siempre en el momento de la recogida de datos, cuando sus futuros usos son aún inciertos). Además, las consecuencias son acumulativas, y no pueden ser evaluadas adecuadamente en una serie de operaciones aisladas. Estos problemas estructurales en la toma de decisiones sobre datos personales suponen un cambio esencial. No se trata solo de que es más difícil proteger la privacidad, sino que cambia el carácter del riesgo: el de la toma de decisiones basadas en el tratamiento de los datos (MaYer-Schönberger y CuKIER, 2013: 188). 
del panóptico, se ha mostrado cómo nuestras actividades públicamente observables, que se dispersan en el espacio y el tiempo, se reúnen y hacen visibles desde un solo punto, construyendo una imagen bastante detallada de nuestra vida privada (REIMAN, 1995: 29). La tecnología del panóptico induce al individuo a un «estado de consciencia y visibilidad permanente que aseguran el funcionamiento automático del poder» (Foucault, 1982: 207-208). Pero se produce la paradoja de que junto a esa imagen de un control centralizado de nuestras vidas, la difusión y procesamiento de los datos se ha interpretado también recurrentemente bajo la imagen de una cultura generalizada de vigilancia representada en la famosa ficción orwelliana que ha sido ahora internalizada por todos los agentes públicos y privados: el espacio social digital está sumido en el voyerismo y la vigilancia (STAPLES, 2000: 130). Esa vigilancia u observación permanente es ahora flexible y móvil y se filtra en los más diversos ámbitos de la vida, contribuyendo los propios vigilados a proporcionar la información (BAUMAN y LYON, 2013). Se expande ilimitadamente, así, la vigilancia y el control de la privacidad y el riesgo de suprimir la individualidad y, con ella, la posibilidad de pensamientos, ideas y acciones propias (SCHWARTZ, 1999).

\section{LA DIMENSIÓN SOCIAL DE LA PRIVACIDAD}

La dimensión social suele dejarse de lado desde el enfoque restrictivo dominante, que ha sido calificado como «autogestión de la privacidad» (Solove, 2013). Este asume que el objetivo de la protección de la privacidad es proporcionar a las personas el control sobre sus datos personales, permitiéndoles decidir cómo evaluar los costos y beneficios de recopilar y utilizar su información. Este marco es insuficiente en cuanto no toma en consideración que la privacidad es un valor que tiene relevancia social (REGAN, 1995; Roessler y MoKrosinska, 2015). La cesión de los datos excede la elección individual, en cuanto que afecta a los fundamentos de las reglas sociales (Llaneza, 2019: 16). Podrían señalarse diversas bases que sustentan esta dimensión social del valor de la privacidad. Me voy a referir a cuatro de ellas: en primer lugar, la privacidad es un valor colectivo que requiere ser protegido entre todos; en segundo lugar, es un valor constitutivo de la democracia; en tercer lugar, lo privado debe contribuir a la pluralidad de la esfera pública; y, por último, tiene no solo una dimensión negativa de protección, sino también una dimensión positiva de control y participación, en cuanto que la mayoría de nuestras acciones y decisiones privadas está mediada o es facilitada por un oscuro entramado institucional que requiere transparencia y control públicos.

\section{Privacidad como bien colectivo}

La privacidad es un bien colectivo o público porque no puede ser proporcionado, manejado ni protegido de forma privada en el complejo contexto institucional comunicativo existente (REGAN, 2015: 62-65). Las relaciones en que están insertos los individuos que 
generan registros de datos son de tal extensión y magnitud que no existen opciones reales de proteger la propia vida íntima de modo individual. Prácticamente todas las esferas de interacción social están en nuestros días mediadas por las tecnologías de la información, al tiempo que el modo en que los datos se gestionan y difunden se ha vuelto demasiado complejo para que el usuario lo administre y controle. La regulación de la privacidad debería contribuir a alejar a las personas de la irracionalidad y la indiferencia al proporcionar información personal y a proteger a los más vulnerables (Allen, 2011) ${ }^{18}$.

Pero, por otra parte, los datos personales tienen también un valor colectivo en el sentido de que constituyen un recurso común con utilidad general. Los poderes públicos deben contribuir a que ese valor que se ha creado colectivamente esté orientado del mismo modo al bien general. Ámbitos como la investigación científica, especialmente en el área de la salud, o la prestación de servicios públicos y la organización de los espacios públicos pueden verse enormemente beneficiados por el uso y tratamiento de datos que está ya presentando resultados muy alentadores. La protección de la privacidad puede suponer restringir muchos de tales usos cuando los datos contienen información personal. Pero el modo de enfrentar este problema no es presentando la privacidad como un derecho que entra en conflicto con otros, sino considerando el modo en que pueden ser adecuadamente especificados los deberes asociados a la privacidad sin ser un obstáculo a otros valores. Puesto que la determinación de los deberes se inscribe en contextos concretos y cambiantes, cuáles hayan de ser los deberes que genera la protección de la privacidad habrá de tener en cuenta el nuevo contexto digital, pudiendo no corresponder por completo con las implicaciones normativas de la privacidad en otras circunstancias (Vayena y Tasioulas, 2016: 9-10).

Los intereses a los que sirve la privacidad no tienen que ser atendidos necesariamente confiriendo al titular del derecho el control exclusivo sobre el flujo de datos, asumiendo, por otra parte, que siempre es posible contar con ese consentimiento, lo cual está lejos de ser obvio. El énfasis exclusivo en la protección de la intimidad puede dejar infrautilizados datos con enorme potencial público. Incluso si se reconoce que existe un interés legítimo en que otros no accedan a nuestra información personal sin autorización, las circunstancias y otros intereses igualmente valiosos son los que determinan si aquel interés genera un deber de protección y bajo qué condiciones. La regulación de la privacidad, desde esta perspectiva, debe orientarse a regular las condiciones bajo las cuales se permiten ciertos usos de datos, evitando los riesgos de discriminación y estigmatización, generando controles y habilitando oportunidades de elección individual. Por ello, «el problema más acuciante que suscita la protección de la intimidad frente a la informática no es tanto el impedir el proceso electrónico de informaciones, que

18. Carlos Fernández Barbudo considera que esta dimensión colectiva de la privacidad obliga a pensar en modos de protección que atiendan a la desigual relación de poder existente y proporcionen instrumentos de actuación y negociación colectiva, contribuyendo a un reparto también colectivo de los intereses generados por la explotación de los datos personales (2019b: 284). 
son necesarias para el funcionamiento de cualquier Estado moderno, sino el asegurar un uso democrático de la information technology" (PÉREz LuÑo, 2017: 345, 348). La recopilación de datos debe ser la mínima necesaria para un propósito legítimo y la transmisión y uso posterior de esa información ha de ser solo para propósitos compatibles con la recopilación inicial. Tales propósitos deben a su vez atender intereses públicos y no orientarse solo a la obtención de ganancias privadas. En todo caso, la cuestión de las condiciones y límites del uso de datos es una cuestión ética, pero, también, política, que habrá de decidirse entre todos (TAsioulas, 2016, p. 7).

\section{Privacidad como elemento constitutivo de una sociedad democrática}

La privacidad es un elemento constitutivo de la democracia (Schwarz, 1999). Es un elemento estructural de la vida democrática, en cuanto fundamento de una ciudadanía reflexiva (Cohen, 2013) y base para la libertad, la igualdad y la pluralidad (CoHen, 1996). Uno de los primeros autores que resaltaron la dimensión social de la privacidad escribió que el respeto a la misma enriquece la interacción social y personal al proporcionar contextos para el desarrollo de diversos tipos de relaciones y múltiples dimensiones de la personalidad (Schoeman, 1984: 413). La posibilidad de separarse de las presiones y el escrutinio colectivo capacita para formar juicios propios y disentir de las posiciones dominantes y reflejarlo en nuestra participación, asociación y expresión públicas. Ciertamente un exceso de privacidad puede servir para desmantelar la democracia, en cuanto favorecería una ciudadanía despreocupada de sus responsabilidades públicas. La democracia habrá de ser el resultado de un ajuste constante entre el derecho a ser dejado solo y las necesidades públicas. «Lejos de considerarse un elemento constitutivo de una sociedad democrática, la privacidad aparece como una contradicción tolerada, cuyas implicaciones deben reconsiderarse continuamente» (Simitis, 1987: 732). Pero la garantía de la capacidad de reflexión y elección personales es una condición indubitada de la democracia, que debe marcar los límites de la acción estatal. La garantía de la libertad y la igualdad individuales obliga a marcar una cierta separación entre lo privado y lo público, entre las elecciones personales y las elecciones colectivas (LEVER, 2013: 41,90 y ss.).

Lo anterior no implica la obligación de proteger todas las elecciones personales, sino la igual capacidad de todo sujeto para decidir qué fines cree razonables, valiosos o correctos; para perseguir sus propias concepciones del bien libremente y como un igual respecto de los demás. La importancia de reconocer que las personas tienen un interés en decidir acerca de su propia vida radica en que la otra cara del mismo es el deber de escuchar y respetar las opiniones morales de los demás, en lugar de asumir que estas pueden ser simplemente descartadas como infundadas o sin sentido siempre que entren en conflicto con nuestros intereses. El valor político de la privacidad complementa, así, su valor personal, siendo ambos relevantes: la capacidad para participar es tan valiosa como los aspectos de nuestra vida dedicados al cuidado de los demás o la búsqueda de 
la felicidad, la verdad, la belleza, la fama o la excelencia (Lever, 2013: 97, 113). Ambos intereses no tienen por qué contradecirse.

El peligro radica en que lo personal y privado se use y manipule para determinar la acción política al margen de la participación consciente y reflexiva. Como afirma Morozov, uno de los más conocidos críticos del ciberutopismo, los ciudadanos no pueden ser simples proveedores de información para tecnócratas que todo lo ven y optimizan. Debería detenerse la deriva hacia un gobierno de los algoritmos en el que los ciudadanos pueden relajarse y dedicarse a sus preocupaciones privadas. La privacidad, además de un valor personal, es un medio para una democracia efectiva, haciendo de los ciudadanos sujetos, y no objetos, de las decisiones públicas. «Queremos espacios privados porque todavía creemos en nuestra capacidad de reflexionar sobre lo que aflige al mundo y encontrar una manera de solucionarlo, y preferiríamos no entregar esta capacidad a los algoritmos». Y el Big Data, con sus muchas bases de datos interconectadas que se nutren de información y algoritmos de dudosa procedencia, impone severas restricciones a la forma en que maduramos política y socialmente (Morozov, 2013).

\section{Esfera pública digital y privacidad}

Las redes sociales se han convertido en una extensión de la vieja esfera pública, suministran información y proporcionan un espacio para la discusión de asuntos políticos y sociales ${ }^{19}$. Existe ya una abundante literatura sobre el potencial de las redes sociales y operadores en Internet para fomentar y organizar vínculos sociales y formas de agregación política que regeneren la vida política, favoreciendo la participación plural y la incorporación de voces y problemas a la discusión pública. El entorno digital desempeña un papel esencial como prolongación del espacio público del discurso y las asociaciones. En sentido habermasiano, los problemas que se reflejan en el ámbito público «toman sus impulsos de la elaboración privada de problemas sociales que tienen resonancia en la vida individual» (1998: 446). Las asociaciones y movimientos sociales trasladan a la esfera pública las necesidades y preocupaciones particulares y privadas. Pero el proceso histórico de formación de la opinión pública no ha sido universalmente incluyente. La separación liberal entre lo público y lo privado ha resultado opresiva y excluyente respecto de las preocupaciones de ciertos individuos y grupos que reivindican en vano la publicidad de sus posiciones y percepciones. Las luchas contra la opresión en el mundo moderno siempre han comenzado redefiniendo asuntos que hasta ese momento se consideraban privados como cuestiones de interés público, problemas de justicia o instancias de poder que necesitan legitimación. «La publicidad democrática requiere garantías positivas de oportunidades para que las minorías convenzan a otros de que

19. Resolución de la Asamblea Parlamentaria del Consejo de Europa, «Social media: social threads or threats to human rights?», Comité de Cultura, Ciencia, Educación y Medios de Comunicación, redactada por José Cepeda, marzo, 2019: 6. 
lo que en el pasado no era público en el sentido de ser una cuestión de interés común ahora debería volverse tal» (FrASER, 1992: 129). Lo privado y lo público no apelan así a esferas perfectamente delimitadas. En el discurso político, son términos poderosos que se emplean con frecuencia para deslegitimar algunos intereses, puntos de vista 0 problemas y para revalorizar otros. Qué sea lo privado no puede ser inaccesible al planteamiento crítico y reflexivo que caracteriza lo público. Y, a la inversa, lo público debe completarse con la propuesta crítica de quienes desde los márgenes luchan porque su experiencia, perspectivas y necesidades no sean despolitizadas. En una sociedad plural, la definición de algo similar al bien común solo puede ser el resultado de la interacción pública, que expresa, en lugar de ocultar, las particularidades (Young, 1990: 119). De este modo, la línea divisoria entre lo privado y lo público es renegociada y rearticulada en el propio discurso público, pudiéndose establecer de muchas y distintas maneras (Benhabib, 2006: 128).

Esa prolongación de lo privado hacia lo público puede contribuir a una acción común más incluyente. En el modelo arendtiano, alcanzamos nuestra humanidad, no en solitario, sino en un mundo plural compartido. No es desde un mundo introspectivo desde donde se construye y se afirma la propia existencia, sino desde la interrelación con los otros compartiendo un mundo común. Su posibilidad «radica en la simultánea presencia de innumerables perspectivas y aspectos en los que se presenta el mundo común y para el que no cabe inventar media o denominador común» (ARENDT, 2005: 77). Al aparecer y actuar junto a otros cada uno puede desarrollar sus posibilidades de ser distinto, lo que supone la capacidad de penetrar en el espacio público con nuevas subjetividades y nuevas narrativas (2005: 206). Así, si la perspectiva liberal de la privacidad implica la protección del individuo frente al ámbito de la acción colectiva, la perspectiva política o democrática supone que la acción colectiva se organice de tal modo que incorpore circunstancias personales de los gobernados.

Las redes sociales aumentan la posibilidad de que los puntos de vista, opiniones y asuntos individuales se incorporen a la esfera pública. Las tecnologías de la información tienen el potencial de generar modos de integración en cuanto que favorecen la puesta en común de una pluralidad de posiciones particulares. Permiten hacer visible y llevar a la esfera pública preocupaciones y necesidades que no llegan a incorporarse al debate político-institucional. Frente al distanciamiento y extrañamiento del espacio público característico del modelo liberal, el espacio digital podría favorecer el acercamiento y preocupación por los otros plurales y diversos. Pero la realidad no está siendo completamente así.

Las plataformas digitales sociales se han convertido en marcos que, al hacer accesible el conocimiento y favorecer la interacción y la formación de la opinión pública, disponen de un grado relativo de poder y responsabilidad (Jaume Palasí y Spielkamp, 2017: 18). La compleja organización actual de las tecnologías de la información basada en algoritmos gobierna de hecho, puesto que conforme a ellos se decide qué información se incluye en un análisis; se prevén, planifican y ejecutan transformaciones en los datos; y actúan como filtros y espejos, seleccionando y reflejando la información que 
tiene sentido dentro de la lógica computacional del algoritmo y de las culturas humanas que crearon esa lógica (ANANny, 2016: 97-98). Estos sistemas socio-técnicos no son simplemente sistemas de información tecnológica, sino sistemas complejos interdependientes de artefactos técnicos, prácticas culturales, actores sociales y significados situados (REGAN, 2015: 51). Se habla, en este sentido, de las tecnologías regidas por algoritmos como instituciones debido a su poder para estructurar los comportamientos de los usuarios, influir en la formación de preferencias y configurar decisiones acerca de la producción de contenidos mediante mecanismos que son de naturaleza tecnológica pero que se desarrollan en el marco de procesos sociales complejos (NApOLI, 2014: 343). Las instituciones estructuran y moldean la vida social, determinando y constrińendo las actuaciones individuales y colectivas. En el marco del entramado institucional de las tecnologías de la información, tanto los comportamientos individuales como las conversaciones públicas se ven informados y restringidos por el modo en que el conocimiento se construye y codifica institucionalmente. No es propiamente una estructura de poder esencialmente político o económico, sino de un tipo diferente de naturaleza corporativa.

Y la realidad de esa estructura institucional digital es la de una acción fragmentada, manipulada y cada vez más polarizada. Las tecnologías digitales contribuyen a una simplificación excesiva de la pluralidad para ajustarla a modelos genéricos. Discriminan la información que recibe cada sujeto en función de sus intereses y perfil ideológico, reforzando, de este modo, sus prejuicios, contribuyendo a la formación de sectores enfrentados y fragmentando el cuerpo político. Los denominados filtros burbuja seleccionan y restringen la información que llega a cada individuo, aislándole en grupos ideológica y culturalmente afines y desconectándole de informaciones que desafíen sus posiciones. Esta segregación de la información no solo tiene un efecto negativo en la autonomía individual, sino también en la esfera política. La información sesgada reduce la pluralidad y dificulta el intercambio de puntos de vista y la posibilidad de acceder a información diversa, que es la que permitiría cuestionarse las posiciones propias e incentivar la crítica y el disenso. Asimismo, las instituciones mediadoras del espacio público digital generan y albergan públicos diversos con poca o nula interrelación entre ellos y con carácter efímero, dependiente del contenido de la deliberación, desapareciendo la pluralidad del mundo común. El problema que esto supone es que el espacio público se limita a ser la repetición de una particularidad concreta en lugar de reflejar la diversidad del mundo y, por tanto, la igualdad es más de carácter identitario que de capacidad de juicio (Fernández Barbudo, 2019a: 155, 159-161).

Para que las potencialidades de la esfera pública digital como esfera incluyente puedan llegar a ser reales son necesarias ciertas precondiciones, como su carácter accesible, seguro y abierto. La privacidad es una de esas precondiciones esenciales. El discurso público presupone individuos autónomos con capacidad de reflexión y crítica. $\mathrm{Al}$ mismo tiempo, la confidencialidad y el anonimato se hacen necesarias en una esfera pública integradora. "¿Quién va a hablar o escuchar cuando este comportamiento deje 
rastros de datos detallados de una manera que sea difícil de entender o anticipar?» (SCHWARTZ, 1999: 1650-1651) ${ }^{20}$.

\section{Privacidad y control sobre el proceso}

El entorno digital está generando una estructura de poder difusa y desigualitaria cuyo control viene exigido por la dimensión social de la privacidad. Considerar la privacidad como un interés social implica cambiar el enfoque: no es tanto que el individuo sea el que tenga la opción de controlar la información que le atańe cuanto que sea posible controlar de modo colectivo la propia organización de la información para que pueda aparecer como justificada ${ }^{21}$. Si la extensión de la idea de intimidad a la esfera privada supone la idea de control sobre lo que se revela y lo que no, la dimensión social de la privacidad alude al control sobre el proceso que de modo difuso hace que nuestros datos sean recopilados, procesados y usados. La metáfora que expresa esta situación no es tanto la del Gran Hermano o el Panóptico y su imagen de vigilancia extrema cuyo fin es la supresión de la individualidad, sino la de El Proceso de Franz Kafka (Solove, 2001: 1419 y ss.). Su descripción de los poderes oscuros capta el sentido de indefensión, frustración y vulnerabilidad que se experimenta cuando una organización o estructura tiene control sobre muchos detalles de nuestras vidas sin que nosotros sepamos qué ocurre (¿quién sabe qué? ¿cuánto saben? ¿cómo nos afecta ese conocimiento? ¿para qué se va a emplear?) y cuando las decisiones son adoptadas sobre la base de esos datos sin que tengamos ninguna capacidad de participar en la adopción de la decisión ni de defendernos frente a ella ${ }^{22}$. De acuerdo con esta metáfora, el problema principal del procesamiento de datos es el modo en que se trata a los individuos y a la información

20. La cuestión es más amplia que la de la participación en redes sociales y puede plantearse con otras tecnologías que emplean la inteligencia artificial, como el empleo de técnicas de reconocimiento facial para identificar y vigilar en espacios públicos.

21. La cuestión de la privacidad ya no se limita a si los datos personales deben ser recopilados y procesados, sino que versa también sobre cómo deberían ser usados esos datos. Las normas jurídicas deben constituir las condiciones para que el uso de la información personal no impida que los individuos se liberen de la intimidación por parte del Estado o la comunidad (SCHWARTZ, 1994: 559 y 561). Zarsky considera que el proceso de tratamiento de datos debe ser «interpretable» en el sentido de que las razones de las decisiones a las que conducen los algoritmos sean comprensibles para los humanos y tales decisiones no sean sin más el resultado de correlaciones de hechos previos (ZARSKY, 2013: 305-306). En otro momento, el autor afirma que "si los individuos se ven afectados por el modelo predictivo, tienen derecho a entender por qué. Deben recibir una explicación sobre los criterios de decisión y la lógica detrás de estas acciones» (ibídem: 317). Marmor habla de que cualquier cambio o manipulación en el entorno que hace razonablemente predecible el flujo de las informaciones personales que disminuya significativamente la capacidad de controlar la información que se revela tendría que poder ser justificado adecuadamente (2014: 11).

22. Paul Schwartz considera que la insuficiencia del modelo de privacidad como control de los datos por el individuo para el entorno virtual se debe a cuatro causas: la «brecha de conocimiento», relativa a la ignorancia generalizada con respecto a los términos que regulan la difusión en Internet de la información personal; la "falacia de consentimiento" y la "trampa de la autonomía», consecuencia de las circunstancias en que se acuerda el uso de datos que resultan insuficientes para considerar el consentimiento informado y voluntario y convierten los actos formales de consentimiento en un ritual vacío; y, por último, la ilusión del aislamiento 
relativa a ellos, conforme a una estructura informal que obedece a lógicas y sistemas diversos ajenos al sujeto (de carácter económico, cultural, político, estratégico, etc.). Los procesos de toma de decisiones formalizados «se ejercen cada vez con mayor frecuencia en una esfera más amplia de nuestras vidas, y tenemos poco poder y poco que decir dentro de un sistema de este tipo, que tiende a estructurar nuestra participación en formas estandarizadas que no nos permiten alcanzar nuestras metas, deseos y necesidades» (Solove, 2001: 1422).

La privacidad en este sentido aparece como una cuestión acerca del poder en nuestras sociedades. El problema del manejo de datos personales es que desempodera a las personas, les deja sin un control significativo de sus vidas. Las define y juzga conforme a los datos disponibles, sacados de su propio contexto, agregados y categorizados. Muchas decisiones se adoptan sobre la base de esos bits de información que se identifican sin más fundamento con conocimiento sobre la persona (Rosen, 2000). No es el sujeto en sí el que toma decisiones, sino que las decisiones se adoptan de modo semi-automatizado sobre la base de criterios respecto de los que no existe suficiente control ni transparen$\mathrm{cia}^{23}$. Para que esas decisiones puedan aceptarse como justificadas deberían satisfacer una serie de exigencias, tales como que la información haya sido tratada de modo reflexivo, que las personas sean consideradas con respeto y dignidad, o que tengan una participación significativa en el uso y resultados de la información (Solove, 2001: 1461-1462). Se ha hablado, en este sentido, del «debido proceso tecnológico» en relación con las garantías de control e imparcialidad exigibles tanto respecto del diseño y uso de los algoritmos predictivos como respecto de la toma de decisiones individuales conforme a ellos (Citron y Pasquale, 2014: 19; Steinbock, 2005).

Las responsabilidades en la modificación de la situación actual y la consolidación de estructuras justificadas y transparentes para el procesamiento de datos han de recaer tanto en las autoridades públicas como en las organizaciones privadas. Podría hacerse extensiva a la situación de injusticia generada por la infraestructura socio-técnica de información de nuestros días el modelo de la responsabilidad en contextos de injusticia estructural de Iris Marion Young. Conforme al mismo, la responsabilidad de cada agente para rectificar la injustica estructural depende de las posiciones que ocupan respecto a tal estructura. Para ello proporciona una serie de parámetros de razonamiento que puede emplear cada agente u organización para determinar lo que debe hacer. Tales parámetros son: la posición de poder o de influencia sobre los procesos que producen la injusticia; la situación de privilegio o de beneficio respecto de tales procesos; el interés en la superación de la injusticia; y la capacidad colectiva para cambiar la situación injusta, esto es, la importancia de la organización para ejercer más eficazmente la responsabilidad (Young, 2011: 150-154). Es indudable que los operadores digitales

de los datos (SCHWARTz, 1999: 1660-1663 y 1682-1685). El autor habla de una «infraestructura técnica opaca» que condiciona la privacidad en Internet (1990: 1683).

23. No se trata solo de descifrar los códigos algorítmicos, sino de desentrañar el entramado de decisiones humanas y no humanas que configuran una estructura de códigos, normas y prácticas que funcionan con poca transparencia (ANANNY, 2016: 98-99). 
privados han adquirido una responsabilidad especial debido al enorme poder que les confiere la ingente cantidad de datos que poseen y pueden usar, el control que ejercen sobre las herramientas tecnológicas que se emplean para recopilarlos y tratarlos y los enormes beneficios económicos que todo ello les reporta. De ahí, el deber especial del sector privado de actuar con imparcialidad, transparencia y responsabilidad bajo la guía de instituciones publicas, que han de velar por la garantía de los bienes y fines colectivos asociados a la privacidad. Determinar si la vía de la «responsabilidad proactiva» comenzada por el Reglamento General de Protección de Datos europeo, es la más adecuada para traducir jurídicamente aquella responsabilidad es una cuestión que excede la pretensión de este trabajo. El modelo se inspira en la idea anglosajona de la accountability como exigencia moral y política de hacerse responsable de las acciones propias, pero el riesgo de que esta construcción acabe siendo un elemento burocrático más sin virtualidad para hacer efectivamente responsables a las empresas de abordar la analítica de datos «desde la perspectiva de perseguir el bien común» (MARTínez, 2017: 161) merece un tratamiento sosegado.

\section{CONCLUSIONES}

A lo largo del recorrido por los ámbitos de la privacidad han ido apareciendo una pluralidad de intereses dignos de protección. Tales intereses se podrían agrupar en torno a la capacidad y responsabilidad del individuo de pensar, elegir, vivir y participar. En el primer grupo se englobarían la posibilidad de aislamiento y la aspiración a un espacio libre de evaluaciones y riesgos, sin interferencia o vigilancia. El segundo grupo incorpora la capacidad de hacer elecciones autónomas, de elegir un plan de vida propio y de apropiación crítica de las tradiciones y culturas, teniendo el control de las decisiones relevantes que afectan al propio sujeto. En este sentido, la privacidad protege al individuo en su personalidad particular, en sus decisiones propias que no vienen impuestas por modelos abstractos de sujeto, ofreciéndole un control sobre la definición de sí mismo que se proyecta al exterior. Al tercer grupo pertenecería la libertad para perseguir y desarrollar las elecciones hechas, el interés en formar y mantener relaciones íntimas y asociativas diversas, teniendo la capacidad de elegir cómo queremos presentarnos ante los demás y presentar diferentes aspectos de nosotros mismos en diferentes contextos. Inaccesibilidad, confidencialidad y control sobre los modos en que los demás se inmiscuyen en nuestra vida íntima o nos fiscalizan integran la privacidad en este sentido, que incluye el control sobre la información de datos personales especialmente sensibles. Si la privacidad ampara las condiciones para la constitución autónoma del individuo y el respeto a las diferencias particulares, en el cuarto grupo se ubicarían los intereses de todo individuo a ser tratado como par por el resto de miembros de la comunidad, como ser digno de respeto y dotado de capacidad decisoria en el marco de un mutuo reconocimiento. Este sentido está especialmente presente en la dimensión social y política de la privacidad. Adquiere especial significación en el entorno digital, incluyendo 
intereses relativos a un uso democrático de las tecnologías de la información, entre los que me he referido al control sobre el proceso institucional de recopilación y uso de datos, al interés en conocer de modo no fragmentario ni sesgado las informaciones públicas y participar en los esquemas de justificación de los sistemas socio-técnicos que condicionan decisiones y acciones o a la capacidad de penetrar en lo público desde nuestras posiciones y preocupaciones. Todo ello está en juego en nuestras discusiones sobre la privacidad.

Si los intereses son diversos también debe serlo el modo en que se pueden configurar las medidas protectoras. No requiere lo mismo la garantía de un espacio de aislamiento libre de vigilancia y riesgos que la reglamentación del marco institucional que puede hacer posible una esfera pública igualitaria y plural. Estos son, quizá, los aspectos más relevantes a tener en cuenta al reflexionar en nuestros días sobre la privacidad. Por una parte, evitar la destrucción de la personalidad y el acaparamiento de lo íntimo por la agregación de datos y la generación de perfiles que simplifican en exceso la complejidad de la subjetividad y que no respetan la forma en que el propio sujeto percibe su singularidad, poniéndolo a disposición de intereses que le trascienden. Por otra parte, reglamentar el uso de las tecnologías de la información para convertirlas en un espacio público igualitario, plural y abierto. La solución a los principales problemas de la privacidad pasa necesariamente por una solución normativa. Es necesaria una regulación del entorno digital que haga posibles diseños que tengan en cuenta los intereses personales y públicos que están detrás de la privacidad. El modelo para ello no puede quedar reducido a un modelo de autogestión de la privacidad que no tiene en cuenta que poner en riesgo la privacidad es, sobre todo, poner en riesgo un modelo de lo público democrático y plural.

\section{BIBLIOGRAFÍA}

Alexander, Sally, 1998: «Una habitación propia: las utopías de las mujeres en los años 20», Arenal. Revista de Historia de las mujeres, 5 (1): 131-150

Allen, Anita, 1988: Uneasy Access. Privacy for Women in a Free Society, New Jersey: Rowman \& Littlefield Publishers

Allen, Anita, 2011: Unpopular Privacy: What Must We Hide?, New York: Oxford University Press

Amorós, Celia, 1991: Hacia una crítica de la razón patriarcal, Barcelona: Anthropos

Ananny, Mike, 2016: «Toward an ethics of algorithms convening, observation, probability, and timeliness», Science, Technology \& Human Values, 41 (1): 93-117

Arendt, Hannah, 2005: La condición humana, Barcelona: Paidós

Asamblea Parlamentaria del Consejo de Europa, 2019: Resolución sobre "Social media: social threads or threats to human rights?», Comité de Cultura, Ciencia, Educación y Medios de Comunicación, redactada por José Cepeda

Baudelaire, Charles, 2009: «El pintor de la vida moderna», Arte y Modernidad, Buenos Aires: Prometeo Libros 
Bauman, Zygmunt y Lyon, David, 2013: Vigilancia líquida, Barcelona: Paidós

BéJar, Helena, 1988: El ámbito intimo. Privacidad, individualismo y modernidad. Madrid: Alianza

Benhabib, Seyla, 2006: «Modelos de espacio público. Hannah Arendt, la tradición liberal y Jürgen Habermas», en El ser y el otro en la ética contemporánea. Feminismo, comunitarismo y posmodernismo, Barcelona: Gedisa: 105-138

BoK, Sissela, 1983: On the Ethics of Concealment and Revelation, New York: Vintage Books

CAmps, Victoria, 1989: "La reconstrucción de lo público y lo íntimo», en Castilla del Pino (ed.), De la intimidad, Barcelona: Crítica: 59-75

Castells, Manuel, 2009: Comunicación y poder, Madrid: Alianza

Castilla del Pino, Carlos, 1989a: Introducción a Castilla del Pino (ed.), De la intimidad, Barcelona: Crítica: 9-16

Castilla del Pino, Carlos, 1989b: «Público, privado, íntimo», en Castilla del Pino (ed.), De la intimidad, Barcelona: Crítica: 25-31

Cate, F. H., 2000: «Principles on Internet Privacy», Connecticut Law Review, 32: 877-896

Citron, Danielle y Pasquale, Frank, 2014: «The Scored Society, Due Process for Automated Predictions», Washington Law Review, 89: 1-33

Cohen, Jean L., 1996: «Democracy, Difference and the Right of Privacy», en S. Benhabib (ed.), Democracy and Difference: Contesting the Boundaries of the Political, Princeton: Princeton University Press: 187-217

Cohen, Jean L., 1999: «Para pensar de nuevo la privacidad: la autonomía, la identidad y la controversia sobre el aborto", Debate Feminista, 19: 9-53

Cohen, Julie E., 2013: «What privacy is for?», Harvard Law Review, 126 (7): 1904-1933

DíAz Rojo, José Antonio, 2002: «Privacidad: ¿neologismo o barbarismo?», Espéculo. Revista de estudios literarios, Universidad Complutense de Madrid

Dworkin, Ronald, 2003: Virtud soberana. La teoría y la práctica de la igualdad, Barcelona: Paidós

Fernández Barbudo, Carlos, 2019a: «El nuevo concepto de privacidad: la transformación estructural de la visibilidad», Revista de Estudios Políticos, 185: 139-167

Fernández Barbudo, Carlos, 2019b: «Privacidad (digital)», Eunomía. Revista en Cultura de la Legalidad, 17: 276-288

Foucault, Michel, 1982: Vigilar y castigar. Nacimiento de la prisión, México: Siglo XXI

Fraser, Nancy, 1992: «Rethinking the Public Sphere: A Contribution to the Critique of Actually Existing Democracy», en Craig Calhoun (ed.), Habermas and the Public Space, Cambridge: The MIT Press: 109-142

Fried, Charles, 1968: «Privacy», The Yale Law Journal, 77 (3): 475-493

Garriga Domínguez, AnA, 2018: "La elaboración de perfiles y su impacto en los derechos fundamentales. Una primera aproximación a su regulación en el Reglamento General de Protección de Datos de la Unión Europea», Derechos y libertades, 38: 107-139

Garzón Valdés, Ernesto, 2003: «Lo íntimo, lo privado y lo público», Claves de Razón Práctica, 137: $14-24$

Gavison, Ruth, 1980: «Privacy and the Limits of Law», Yale Law Journal, 89: 421-71

Gerstein, Robert S., 1978: «Intimacy and Privacy», Ethics, 89 (1): 76-81

Habermas, Jürgen, 1998: Facticidad y validez. Sobre el Derecho y el Estado Democrático de Derecho en términos de Teoría del Discurso, Madrid: Trotta 
Hoven, Jeroen van den, 1997: «Privacy and the Varieties of Informational Wrongdoing», Computers and Society, 27 (3): 33-37

Iglesia, Anna M. a , 2019: La revolución de las flâneuses, Girona: Wunderkammer

Innes, Julie C., 1992: Privacy, Intimacy and Isolation, New York: Oxford University Press

Jaume-Palasí, Lorena y Spielkamp, Matthias, 2017: «Ethics and algorithmic processes for decision making and decision support», AlgorithmWatch Working Paper, 2: 1-18

Kang, Jerry, 1998: «Information Privacy in Cyberspace Transactions», Stanford Law Review, 50: 1193-1294

Laporta, Francisco, 2018: «Los confines del Derecho: una invitación al debate», Revista Jurídica de la Universidad Autónoma de Madrid, 37: 21-44

Lever, Annabelle, 2013: A Democratic Conception of Privacy, Bloomington: Authorhouse

Llaneza, Paloma, 2019: Datanomics, Barcelona: Deusto

Lucas Murillo, Pablo, 1999: «El derecho a la autodeterminación informativa. Observaciones desde la experiencia española», Revista de la Academia de la Magistratura, 2: 23-34

LuCENA-Cid, IsABel, 2012: «La protección de la intimidad en la era teconlógica: hacia una reconceptualización», Revista Internacional de Pensamiento Político, 7: 117-144

Lyon, David, 2007: Surveillance Studies. An Overview, Cambridge: Polity Press

Marcilla, Gema, 2015: «Sistemas de seguridad basados en la vigilancia masiva. Una mirada al Derecho penal de máximos desde las revelaciones de Edward Snowden», en A. Doval (dir.), Nuevos limites penales para la autonomía individual y la intimidad, Pamplona: Aranzadi: 241-280

Margalit, Avishai, 1996: The Decent Society, Cambrige, Mass.: Harvard University Press

Marmor, Andrei, 2014: "What Is the Right to Privacy?», Legal Studies Research Papers Series 14-13: 1-23

MartíneZ, Ricard, 2007: «El derecho fundamental a la protección de datos: perspectivas», Revista de los Estudios de Derecho y Ciencia Política de la UOC, 5: 47-61

Martínez, Ricard, 2014: «Privacidad, EE.UU y Espańa. Tan lejos tan cerca», Telos. Cuadernos de Comunicación e innovación, 97: 1-9

Martínez, Ricard, 2017: "Cuestiones de ética jurídica al abordar proyectos de Big Data. El contexto del Reglamento general de protección de datos», Dilemata, 24: 151-164

Martínez de Pisón, José, 2016: «El derecho a la intimidad: de la configuración inicial a los últimos desarrollos en la jurisprudencia constitucional», Anuario de Filosofía del Derecho, XXXII: 409-430

Mayer-Schönberger, Viktor y Cukier, Kenneth, 2013: Big Data. A Revolution that Will Transform How We Live, Work, and Think, New York: Houghton Mifflin Harcourt

Mill, John Stuart, 1977: «On Liberty», en Robson, John M. (ed.), The Collected Works of John Stuart Mill, vol. XVIII, Essays on Politics and Society Part I, Toronto y London: University of Toronto Press \& Routledge and Kegan Paul

Mittelstadt, Brent D., Allo, Patrick, Taddeo, Mariarosaria, Wachter, Sandra y Floridi, Luciano, 2016: "The ethics of algorithms: Mapping the debate», Big Data \& Society, 3 (2): 1-21

Monasterio, Aníbal, 2017: «Ética algorítmica: Implicaciones éticas de una sociedad cada vez más gobernada por algoritmos», Dilemata, 24: 185-217

Moore, Adam, 2003: «Privacy: Its Meaning and Value», American Philosophical Quarterly, 40: 215-227 
Morozov, Evgeny, 2013: «The Real Privacy Problem», MIT Technology Review, https://www. technologyreview.com/s/520426/the-real-privacy-problem/ (Último acceso 18/10/2019)

Nagel, Thomas, 1998: «Concealment and Exposure», Philosophy \& Public Affairs», 27 (1): 3-30

Napoli, Philip M., 2014: «Automated Media: An Institutional Theory Perspective on Algorithmic Media Production and Consumption», Communication Theory, 24 (3): 340-360

Newport, Cal, 2019: Digital Minimalism: Choosing a Focused Life in a Noisy World, New York: Portfolio/Penguin

Nissenbaum, Helen, 2004: «Privacy as Contextual Integrity», Washington Law Review, 79 (1): 101-139

Parent, William, 1983: «Privacy, Morality and the Law», Philosophy and Public Affairs, 12: 269-88

Pariser, Eli, 2017: El filtro burbuja. Cómo la red decide lo que leemos y lo que pensamos, Madrid: Taurus

Pérez Luño, Antonio Enrique, 2000: «La tutela de la libertad informática en la sociedad globalizada», Isegoría, 22: 59-68

Pérez Luño, Antonio Enrique, 2017: Derechos humanos, Estado de Derecho y Constitución, Madrid: Tecnos, $11 .^{\mathrm{a}}$ ed.

Post, Robert C., 2001: «Three Concepts of Privacy», Georgetown Law Journal, 89 (6): 2087-2098

Rachels, James, 1975: «Why Privacy is Important?», Philosophy \& Public Affairs, 4 (4): 323-333

Regan, Priscilla, 1995: Legislating privacy: Technology, social values and public policy, Chapel Hill: The University of North Carolina Press

Regan, Priscilla, 2015: «Privacy and the Common Good: Revisited», en Roessler, Beate y Mokrosinska, Dorota (eds.), Social Dimensions of Privacy. Interdisciplinary Perspectives, Cambridge: Cambridge University Press: 50-70

Reiman, Jeffrey, 1976: «Privacy, Intimacy, and Personhood», Philosophy \& Public Affairs, 6, (1): $26-44$

Reiman, Jeffrey, 1995: «Driving to the Panopticon: A Philosophical Exploration of the Risks to Privacy Posed by the Highway Technology of the Future», Santa Clara Computer \& High Technology Law Journal, 11: 27-44

Roessler, Beate y Mokrosinska, Dorota (eds.), 2015: Social Dimensions of Privacy. Interdisciplinary Perspectives, Cambridge: Cambridge University Press

Rosen, Jeffrey, 2000: The Unwanted Gaze: The Destruction of Privacy in America, New York: Vintage Books

Schauer, Frederick, 2003: "The Social Construction of Privacy», en Craig L. LaMay, Journalism and the Debate Over Privacy, Mahwah, NJ: Lawrence Erlbaum

Schermer, BART W., 2011: "The limits of privacy in automated profiling and data mining», Computer Law \& Security Review, 27 (1): 45-52

Schoeman, Ferdinand, 1984: «Privacy and Intimate Information», en Schoeman, F. (ed.), Philosophical Dimensions of Privacy, Cambridge: Cambridge University Press: 403-18

Schwartz, Paul M., 1994: «Privacy and Participation: Personal Information and Public Sector Regulation in the United States», Iowa Law Review, 80: 553-618

Schwartz, Paul M., 1999: "Privacy and Democracy in Cyberspace», Vanderbilt Law Review, 52: 1609-1701 
Sibilia, Paula, 2009: La intimidad como espectáculo, Buenos Aires: Fondo de Cultura Económica

Simitis, Spiros, 1987: «Reviewing Privacy in an Information Society», University of Pennsylvania Law Review, 135 (3): 707-746

Solove, Daniel J., 2001: «Privacy and Power: Computer Databases and Metaphors for Information Privacy», Stanford Law Review, 53: 1393-1462

Solove, Daniel J., 2013: "Privacy Self-Management and the Consent Dilemma», Harvard Law Review, 126: 1880-1903

Staples, William G., 2000: Everyday Surveillance: Vigilance and Visibility in Postmodern Life, Oxford: Rowman \& Littlefield Publishers

Steinbock, Daniel J., 2005: "Data matching, data mining, and due process», Georgia Law Review, 40 (1): 1-86

Tasioulas, John, 2016: «Big Data, Human Rights and the Ethics of Scientific Research», accesible en https://www.abc.net.au/religion/big-data-human-rights-and-the-ethics-ofscientific-research/10096298 (último acceso 17/10/19)

Thomson, Judith J., 1975: «The Right to Privacy», Philosophy \& Public Affairs, 4 (4): 295-314

Toniatti, R., 1991: «Libertad Informática y Derecho a la Protección de los datos Personales: Principios de Legislación Comparada", Revista Vasca de Administración Pública, 29: 139-162

Toscano, Manuel, 2017: «Sobre el concepto de privacidad: la relación entre privacidad e intimidad», Isegoría. Revista de Filosofía Moral y Politica, 57: 533-552

Vayena, Effy y Tasioulas John, 2016: «The dynamics of big data and human rights: the case of scientific research", Philosophical Transactions, Royal Society Publishing

Wacks, Raymond, 2010: «Should the Concept of Privacy be Abandoned?», Law, Morality, and the Private Domain, Hong Kong: Hong Kong University Press: 235-248

Wachter, SAndra y MitTelstadt, Brent, 2019: «A right to reasonable inferences: re-thinking data protection law in the age of Big Data and AI», Columbia Business Law Review: 1-85

Wasserstrom, Richard A., 1984: «Privacy: Some arguments and assumptions», en F. Schoeman (ed.), Philosophical Dimensions of Privacy: An Anthology, Cambridge: Cambridge University Press: 317-332

Westin, Alan F., 1967: Privacy and Freedom, New York: Atheneum

Whitman, James Q., 2004: «The Two Western Cultures of Privacy: Dignity versus Liberty», The Yale Law Journal, 113 (6): 1151-1222

Woolf, Virginia, 2008: Una habitación propia, Barcelona: Seix Barral

Young, Iris Marion, 1990: Justice and the Politics of Difference, Princeton: Princeton University Press, Princeton

Young, Iris Marion, 2011: Responsabilidad por la justicia, Madrid: Ediciones Morata

Zarsky, TAL, 2013: «Transparency in Data Mining: From Theory to Practice», en Bart Custers, Toon Calders, Bart Schermer y Tal Zarsky (eds.), Discrimination and Privacy in the Information Society, Berlin: Springer: 301-324

Zuboff, Shoshana, 2019: The Age of Surveillance Capitalism: The Fight for a Human Future at the New Frontier of Power, New York: Public Affairs

$\triangle \quad$ DOXA $43(2020)$ 